\title{
Knowledge and Perception of Students towards Publication Ethics: A Comparative Study in Two Academic Settings
}

\author{
Shayesteh Jahanfar ${ }^{1^{*}}$, Mitra Molaeinezhad ${ }^{2}$ and Dzalila Izzat ${ }^{3}$ \\ ${ }^{1}$ Department of Health Sciences, School of Health Sciences, Central Michigan University, United States of America \\ ${ }^{2}$ Assistant professor, Department of Behavioral Sciences, Isfahan University of Medical Sciences, Iran \\ ${ }^{3}$ Medical officer, Health Center in the University of Technology, Malaysia
}

*Corresponding address: Shayesteh Jahanfar, Department of Health Sciences, School of Health Sciences, Central Michigan University, Mount Pleasant, United States of America, Tel: 9896210181; E-mail: jahan2s@cmich.edu

Received date: April 24, 2017; Accepted date: May 29, 2017; Published date: June 3, 2017

Copyright: ( 2017 Jahanfar S. This is an open-access article distributed under the terms of the Creative Commons Attribution License, which permits unrestricted use, distribution, and reproduction in any medium, provided the original author and source are credited.

\begin{abstract}
Introduction: Publication ethics is a constant concern for academic and students alike as being an author has important academic, social, and financial implications. However, the perception of academics towards matters related to publication ethics is unclear and often a source of conflict.
\end{abstract}

Objective: The aim of this study was to investigate and compare students' perceptions regarding publication ethics in two medical universities.

Method: The target population was selected from two academic settings (Isfahan University, $n=279$, University of Kuala Lumpur, $n=216$ ). Subjects were asked to fill in a standard questionnaire in a cross sectional study design, testing their perceptions towards publication ethics. Simple random sampling was employed. A p value of 0.05 was considered significant.

Result: The result suggests that students from Isfahan had a higher level of knowledge in three areas: publication ethics $(P=0.001)$, funding $(P=0.001)$ and authorship $(P=0.005)$ compared to students from the University of Kuala Lumpur. No significant difference was found between the two groups in terms of reporting the result $(P=0.438)$.

Conclusion: Student training on publication ethics is necessary to prevent academic disappointment and conflict. It is recommended that formal training be added to medical curricula and that publication ethics be practiced in university settings.

Keywords: Health research; Publication ethics; University students

\section{Introduction}

Behavior and attitudes that are acquired by students during medical training lay an important foundation for their ongoing professional practice. One of the important issues relevant to this practice is those behaviors related to academic honesty in health research. The primary role of ethics in health research is to protect the rights, integrity, and standards of research properties. A major part of any research activity is identifying and observing ethical conduct prior to and during the research process.

From the academic point of view, the concept of "publish or perish" has pushed some to "gifted authorship" [1]. It might be speculated that because of seniority, senior scientists are better able to influence the decision on authorship. This view is supported by complaints that senior scientists sign for authorship at the expense of junior researchers [2] or students who are unaware of authorship rights and regulations. There are further indications that authorship is granted to chairpersons of departments as a matter of convention or that senior authors are listed just to increase the possibility of getting accepted for publication [3]. On the other hand, ghost authorship is defined as failure to name as an author an individual who has made substantial contributions to the research or writing of the article. The difficulty in identifying who is or is not an author comes from various definitions of authorship and misconceptions surrounding it. The creativity and originality of thinking and writing is what makes an author an author; it is that for which credit is due. However, with writing comes the responsibility for what is written.

Moreover, a research process can be so complex that no one person alone can accomplish the whole concept of the research, as it involves various stages from setting the hypothesis and objectives, testing and analysing them, and coming up with inferences compatible with the objectives. Therefore, research is a team effort and when there is more than one person involved in the process of research, the conflict of interest brings about clashes and causes problems, such as who is the first author? Who should be credited for what? How and which portion of the research should be published? What are the funding allocations and how should they be acknowledged?

Anecdotal evidence suggests that $10 \%$ to $15 \%$ of all researchers are involved in some form of misconduct or inappropriate research practices at some point in their careers. However, there are no clear guidelines or learning opportunities for either undergraduate or 
graduate students about publication ethics. The objective of this study is to investigate students' knowledge and perception of publication ethics in two different settings with and without formal training.

\section{Method}

This was a cross sectional study with two study sites: Islamic Azad University of Isfahan (IZUI) in the city of Isfahan, Iran, and Royal College of Medicine, Perak, University of Kuala Lumpur (UniKL) in Ipoh city, Malaysia. Two hundred and seventy nine students of medicine, dentistry, and allied health science from IZUI were taken as the target population. This group were then compared with a group of medical students $(n=261)$ from UniKL. The sample size in each center was calculated using EPI-Info software, taking into account the total size of the target population in each study field, an expected frequency of $50 \%$ for level of perception regarding ethical issues surrounding publications, and a worst acceptable result of 55\% with a confidence interval of $95 \%$. The targeted total sample size for each center was 250 . A simple random sampling was employed in both centers. A framework of all the registered students was obtained from the registrar's office for each center. A random table was used to do the random sampling until the sample size was reached.

Ethical approval for this study was obtained from the National Malaysian Research Center and the Ethical Research Committee in Islamic Azad University of Isfahan. The instrument consisted of a standard tested questionnaire based on scenarios adapted from Szirony's study (2004) [4]. The content validity of the questionnaire was tested by the primary author from whom the questionnaire was adapted [5]. It included 6 questions to determine socio-demographic characteristics of subjects, and four other sections each measuring subjects' levels of perception regarding ethics in publication/ presentation (6 questions), funding (4 questions), reporting (6 questions) and authorship (6 questions). Each section contained different scenarios exploring subjects' perception of action, approval or disapproval for a given situation. One mark was allocated for each correct answer. A total score was calculated for each section separately. The maximum score for all sections was 6 except funding with 4 questions.

A pilot study was done using 31 subjects (mean age of $41 \pm 3.2$ ) in a group of postgraduate students $(n=24)$ who participated in a research and methodology workshop at University Putra Malaysia (2007). The content of this workshop did not include ethical considerations. The questionnaire was filled out on the last day of the workshop. Internal reliability of the instrument of the individual constructs delineated in the survey was evaluated using Cronbach's alpha coefficients. The Cronbach's alpha coefficient was found to be 0.8 . These participants were not included in the study. Comprehensibility of the questionnaire was tested by sending the instrument to a panel of five experts to validate the ease of questions. Quality of collected data was checked by double checking the data-entry via two different researchers and data clean-up was performed to ensure the accuracy of data.

There were no language barriers as the Iranian counterparts could speak in Persian language. The questionnaire was translated by a professional translator from English to Persian and then translated back to English, and finally checked by the principal researcher for accuracy. The Malaysian medical students were all familiar with the English language as proficiency in English is an entry requirement to the medical college.

Data collection took place between January and June 2009 Collection of data was done in various time frames, usually at the end of each lecture to ease the sampling. The number of participants invited to the study was recorded. $37.6 \%$ of subjects were reluctant to cooperate on the grounds that they were not interested in the topic, were busy, or were not familiar with the concept as they were new students. Data entry was done by two separate individuals and data clean-up was performed before statistical analysis. There were no missing data. Data analysis was done using SPSS software version $16^{\text {th }}$. Qualitative variables were compared using Chi-square test. A p value of less than 0.05 was considered as a significant value. Quantitative variables were correlated using Pearson test. Mean value of total score of publication, funding, reporting and authorship was associated with socio-demographic characteristics via t-test when the distribution of data was normal and via Mann-Whitney test as a non-parametric test when the distribution of data was found to be skewed.

\section{Result}

\section{Socio-demographic characteristics}

There were a total of 539 subjects responding to the questionnaire with a response rate of $73.1 \%$ for both sites (Table 1 ). The overall mean of age was $21.94 \pm 2.39$ with a minimum of 18 and maximum of 43 years old. The majority of participants were 21 to 22 years of age (35.1\%, $\mathrm{n}=189$ ), with $30.4 \% 20$ years of age and below and $32.7 \% 23$ years of age and above. Total number of males was $202(37.5 \%)$ and the remaining were females $(62.5 \%)$. There were 278 subjects from IZUI and 261 from RCMP, UniKL, of whom $38.6 \%(\mathrm{n}=219)$ were Malay, $3.5 \%(n=20)$ were Chinese, $2.8 \%(n=16)$ were Indians and $1.1 \%(n=6)$ belonged to other races in Malaysia. The majority of our sample population were Muslims $(90.0 \%, \mathrm{n}=485)$ and single $(82.2 \%, \mathrm{n}=443)$ (Table 2).

\begin{tabular}{|l|l|l|l|}
\hline \multicolumn{2}{|l|}{ University of Kuala Lumpur (n=261) } & $\begin{array}{l}\text { No. of respondents/ total no. of } \\
\text { students }\end{array}$ & Response rate \\
\hline Phase 1 & Medicine & $83 / 100$ & $83 \%$ \\
\hline Phase 2 & & $35 / 35$ & $100 \%$ \\
\hline Phase 3aJ & $51 / 69$ & $73.9 \%$ \\
\hline Phase 3aS & $66 / 90$ & $73.3 \%$ \\
\hline Phase 3b & $26 / 53$ & $49.1 \%$ \\
\hline Isfahan University (n=278) & No. of respondents/ total no. of students & Response rate \\
\hline
\end{tabular}


Citation: Jahanfar S, Molaeinezhad M, Izzat D (2017) Knowledge and Perception of Students towards Publication Ethics: A Comparative Study in Two Academic Settings. J Clin Res Bioeth 8: 306. doi:10.4172/2155-9627.1000306

Page 3 of 5

\begin{tabular}{|l|l|l|}
\hline Medicine & $45 / 56$ & $80.3 \%$ \\
Dentistry & $120 / 156$ & $76.9 \%$ \\
Allied Health Science & $113 / 178$ & $63.5 \%$ \\
\hline Total & $539 / 737$ & $73.1 \%$ \\
\hline
\end{tabular}

Table 1: Response rate according to study site.

\begin{tabular}{|c|c|c|}
\hline Variables & Iran $(n=278)$ & Malaysia $(n=261)$ \\
\hline $\begin{array}{l}\text { Age (year) } \\
20 \text { and below } \\
21 \text { and above }\end{array}$ & $\begin{array}{l}74(26.6 \%) \\
204(73.4 \%)\end{array}$ & $\begin{array}{l}90(34.5 \%) \\
170(65.5 \%)\end{array}$ \\
\hline $\begin{array}{l}\text { Gender } \\
\text { Male } \\
\text { Female }\end{array}$ & $\begin{array}{l}93(33.5 \%) \\
185(66.5 \%)\end{array}$ & $\begin{array}{l}109(41.8 \%) \\
152(58.2 \%)\end{array}$ \\
\hline $\begin{array}{l}\text { Religion* } \\
\text { Muslim } \\
\text { Christian } \\
\text { Buddhist } \\
\text { Hindu } \\
\text { Others }\end{array}$ & $\begin{array}{l}263(94.6 \%) \\
15(5.4 \%) \\
- \\
- \\
-\end{array}$ & $\begin{array}{l}222(85.1 \%) \\
7(2.7 \%) \\
12(4.6 \%) \\
4(1.5) \\
16(6.1 \%)\end{array}$ \\
\hline $\begin{array}{l}\text { Marital status }{ }^{*} \\
\text { Married } \\
\text { Single }\end{array}$ & $\begin{array}{l}86(31.0 \%) \\
195(69.0 \%)\end{array}$ & $\begin{array}{l}10(3.8 \%) \\
251(96.2 \%)\end{array}$ \\
\hline
\end{tabular}

Table 2: Socio-demographic characteristics of subjects in the two academic settings $(n=539)\left({ }^{\wedge} \mathrm{p}<0.01^{*}\right.$ Using Chi-square test, none of the comparisons were found to be statistically significant $(\mathrm{p}>0.05))$.

The mean age of UniKL students was $22.00 \pm 2.26$ with a minimum of 18 and maximum of 43 years old. The mean age of Isfahan University participants was $22.40 \pm 2.42$ with a narrower range (19-29). The mean age was higher among Isfahani students $(22.40 \pm 2.42 \mathrm{vs}$. $21.44 \pm 2.26, \mathrm{p}=0.001$; using Mann-Whitney test). Isfahani subjects were also more diverse in terms of their study area as they included a group of students in the field of dentistry, nursing and midwifery. The socio-demographic characteristics of Isfahani participants (such as gender and educational level, using Chi-square test) were similar to that of the Malaysian subjects.

\section{Overall academic characteristics}

Only $7.1 \%$ of students $(\mathrm{n}=38)$ had a history of publication in a peerreviewed journal. Similarly, $12.1 \%(n=65)$ of subjects had presented an original article in a professional seminar or congress. Twenty-five students $(1.7 \%, \mathrm{n}=9)$ had received a grant for research. About $49 \%$
( $n=264)$ of them had some kind of training pertaining to research ethics.

The majority $(51.4 \%, \mathrm{n}=277)$ ranked their perception regarding ethical issues as average, followed by $28.9 \%(n=156)$ who ranked their understanding as good.

A comparison between the academic characteristics of subjects in the two academic settings is shown in Table 3. Significant differences were found between the two settings in history of publication $(\mathrm{P}=0.001)$, receiving funds $(0.001)$, and being educated regarding publication ethics $(\mathrm{P}=0.001)$. Frequency of publication, receiving funds and being educated for publication ethics was higher among Malaysian students. There was a significant difference in terms of self-rated perception of ethical issues in publication between the two groups $(\mathrm{P}=0.003)$.

\begin{tabular}{|l|l|l|l|}
\hline Variable & Isfahan (n=278) & UniKL (n=261) & P value \\
\hline $\begin{array}{l}\text { Have you published a paper in a peer-reviewed professional journal? } \\
\text { Yes }\end{array}$ & $16(3.9 \%)$ & $262(64.4 \%)$ & $239(26.3 \%)$ \\
No & & 0.001 \\
\hline $\begin{array}{l}\text { Have you presented an original article in a professional seminar or } \\
\text { congress? }\end{array}$ & $47(11.5 \%)$ & $18(4.4 \%)$ & 0.449 \\
\hline
\end{tabular}




\begin{tabular}{|c|c|c|c|}
\hline $\begin{array}{l}\text { Yes } \\
\text { No }\end{array}$ & $231(56.8 \%)$ & $243(27.3 \%)$ & \\
\hline $\begin{array}{l}\text { Have you received fund for research? } \\
\text { Yes } \\
\text { No }\end{array}$ & $\begin{array}{l}1(0.2 \%) \\
277(67.9 \%)\end{array}$ & $\begin{array}{l}8(2.0 \%) \\
253(29.9 \%)\end{array}$ & 0.001 \\
\hline $\begin{array}{l}\text { Have you been thought about publication ethics? } \\
\text { Yes } \\
\text { No }\end{array}$ & $\begin{array}{l}80(14.8 \%) \\
198(36.7 \%)\end{array}$ & $\begin{array}{l}184(34.1 \%) \\
77(14.3 \%)\end{array}$ & 0.001 \\
\hline $\begin{array}{l}\text { How do you rank your perception regarding publication ethical issues? } \\
\text { Excellent } \\
\text { Good } \\
\text { Average } \\
\text { Below average } \\
\text { Poor }\end{array}$ & $\begin{array}{l}17(3.2 \%) \\
100(18.6 \%) \\
127(23.6 \%) \\
30(5.6 \%) \\
4(0.7 \%)\end{array}$ & $\begin{array}{l}19(3.5 \%) \\
56(10.4 \%) \\
150(27.8 \%) \\
27(5.0 \%) \\
9(1.7 \%)\end{array}$ & 0.003 \\
\hline
\end{tabular}

Table 3: A comparison between academic characteristics of subjects in the two academic settings (Isfahan, $\mathrm{n}=278$; UniKL, $\mathrm{n}=261$ ).

A comparison between total knowledge scores of the two groups showed significantly higher scores for Isfahani students in publication/ presentation $(\mathrm{P}=0.001)$, authorship $(\mathrm{P}=0.016)$, and funding $(\mathrm{P}=0.02)$, but not in reporting the results $(\mathrm{P}=0.814)$ (Table 4$)$.

\begin{tabular}{|l|l|l|l|}
\hline Academics and students & $\begin{array}{l}\text { Isfahan Univ. } \\
\mathbf{( n = 2 7 8 )} \\
\text { Mean ( } \pm \text { SD) }\end{array}$ & $\begin{array}{l}\text { UniKL } \\
(\mathbf{n}=\mathbf{2 6 1}) \\
\text { Mean( } \mathbf{5} \text { SD) }\end{array}$ & P value \\
\hline $\begin{array}{l}\text { Total score of knowledge about } \\
\text { publication }\end{array}$ & $2.41( \pm 1.25)$ & $1.54(1.09)$ & $0.001^{*}$ \\
\hline $\begin{array}{l}\text { Total score of knowledge about } \\
\text { funding }\end{array}$ & $1.69(0.95)$ & $1.45(0.98)$ & 0.02 \\
\hline $\begin{array}{l}\text { Total score of knowledge about } \\
\text { reporting results }\end{array}$ & $2.06(1.32)$ & $2.03(1.34)$ & 0.814 \\
\hline $\begin{array}{l}\text { Total score of knowledge about } \\
\text { authorship }\end{array}$ & $2.08(1.25)$ & $1.80(1.34)$ & 0.016 \\
\hline
\end{tabular}

Table 4: A comparison between mean (SD) of total scores of knowledge regarding publication ethics in the two academic settings (Isfahan, UniKL) ( ${ }^{*}$ Mann-Whitney test).

\section{Discussion}

The objective of this study was to investigate the perception of students regarding ethics of publication. Our result suggests that Isfahani students had a higher level of knowledge in the areas of publication ethics, funding and authorship when compared with UniKl students. This is despite the fact that more UniKL students selfreported having received training for ethics in publication. No formal training has been offered to the students during university years; It is possible that these students are referring to their training during high school years. However, the university setting is the main battlefield for authorship challenges and worries. Future studies should clarify the exact type of training received by students with a clear timeline.

Isfahani students have higher exposure to formal and informal training regarding publication ethics as a part of their curriculum. An annual conference on research methodology provides a perfect opportunity for them to present their research ideas and communicate with other researchers in their field of interest. Also, an annual national research week in December prepares researchers to participate in a competition to present the results of their research projects, get familiar with various aspects of research methodology, and rise as an expert in their own field of interest. Students in the field of medicine have to pass three credits on "research methodology" where they learn about all aspects of research including publication ethics. As a part of their training, an assignment is given to students to write a paper based on a short-term research project.

Our data suggests that Isfahani students were also more confident in their perception towards publication ethics than their Malaysian counterparts. The total score of knowledge about funding the study result was higher among IZUI students as opposed to their UniKl peer even though the difference was small (1.69 vs. 1.45). This is despite the fact that more UniKl students received study grants $(\mathrm{P}=0.001)$.

Students would also benefit from learning issues pertaining publication ethics may be breached by redundant publication, failure to disclose financial conflicts, omitting a deserving author or adding a non-attributing author. The guidelines published by The International Committee of Medical Journal Editors (ICMJE), also known as Vancouver group, [6] suggests that authorship credits should be based on substantial contributions to conception, design or acquisition of data, or analysis and inference of data, writing the article or revising it critically for important intellectual content, and approval of the final version for publication. It is imperative that all these conditions are met in order to become an author.

Even though in theory these instructions seem to be very straightforward, in practice it often causes disputes. In an academic setting, it is important for both students and supervisors to understand that acquisition of funding, collection of data, or general supervision of the research group by themselves do not justify authorship. Poor understanding of these concepts may lead to conflicts. This is hardly surprising as academics are required to produce publications for promotion or accreditation purposes of their academic institute, while on the other hand postgraduate students' further academic improvement, and in some cases future employment, depends on the 
Page 5 of 5

concept of "publish or perish". It is therefore natural that the principles laid down by editors are often breached. The literature is full of discussions about the issue at hand. Hren's study [7] on perceptions of authorship criteria by medical students, graduate students, doctors and medical teachers concluded that these populations believe an author is someone who has a single or multiple qualifying contributions such as writing the article, analyzing the data or developing the original idea.

Gaberson [8] believes that the mere role of supervisor does not make one an author. She also questions the eligibility of the supervisor to be the author since the faculty member is compensated (with salary and work credit during promotion activities) by guiding students engaged in research. Oberlander [6], however, believes that professors are permanent assets of academic setting who invest professionally and personally in what is often called an ongoing research program. They are expected to support the institute by producing articles in competing pressure for accreditation purposes. In addition, to produce scholarships, professors should apply for grants which mean having established curriculum vitae supporting one's capacity to produce welltrained young researchers. Given the fact that academics are to teach, produce exam questions, vet exams, invigilate, coordinate various activities as module coordinators or department heads, and engage in professional service activities for their department, school, university, profession and community, one is tempted to merge training and research activity in one and hit two targets with one arrow.

Whatever the argument, it is clear that poor perception of publication ethics may add to the dilemmas arising from studentfaculty collaboration in producing publications. It is therefore vital to train both sides. Fresh graduates as young researchers should learn various aspects of good authorship practice in order to prevent and resolve authorship problems. Unethical local customs and practices should be clarified for all parties involved in research activities, including the university management authorities so that they can take action in case of disputes.

Training medical students about publication ethics is a necessity, and many attempts have been made to allocate a place for it in undergraduate medical curricula [9]. The General Medical Council's report on undergraduate medical education recommends the inclusion of "ethics and legal matters pertaining to the practice of medicine" [10].

Other strategies include discussions about authorship at the beginning of research, planning for publications such as the conference abstract, the full paper and supplementary papers and determining who is likely to be most involved in these at the analysis level. Proper communication between authors can clarify misplaced expectations. This is especially true for graduate students who may have long-term professional links to their advisors and fear the consequence of questioning authorship practices $[9,11]$.

Following the instructions for authors of medical journals is another constructive way of producing a stress-free environment for research. According to the American Psychological Association (APA) [12] and American Counseling Association (ACA) [13], manuscripts that are substantially based on students' work (course papers, projects, dissertation or theses) should list the student as the principal author. If the faculty member's contribution went above and beyond the reasonable and customary expectations of a faculty advisor, then the faculty member can be considered as a co-author [14].

The findings from this study can be extrapolated to the same populations under study or to populations with the same sociodemographic characteristics. The representativeness of our sample to this population relates to the variance of the phenomenon under study [15].

\section{Conclusion}

UniKl Students' understanding towards publication ethics should be enhanced in order to provide a harmonious academic environment. This can be done by introducing teaching sessions with proper outlines, discussing authorship rights at the beginning of the research process, and following the standard guidelines.

\section{Acknowledgment}

We would like to thank students and academics alike who took part in the study. The Malaysian results of this study were done for an Elective Research Project supervised by the principal author.

\section{References}

1. Gasparyan AY, Nurmashev B, Voronov AA, Gerasimov AN, Koroleva AM, et al. (2016) The pressure to publish more and the scope of predatory publishing activities. J Korean Med Sci 31: 1874-1878.

2. Mann JI (1997) General Pratice Funding and healthcare costs 315.

3. Smith E, Hunt M, Master Z (2014) Authorship ethics in global health research partnerships between researchers from low or middle income countries and high income countries. BMC Med Ethics 15: 42.

4. Fowler MD, Davis AJ (2013) Ethical issues occurring within nursing education. Nurs Ethics 20: 126-141.

5. Szirony TA, Price JH, Wolfe E, Telljohann SK, Dake JA (2004) Perceptions of Nursing Faculty Regarding Ethical Issues in Nursing Research. J Nurs Educ 43: 270-279.

6. Oberlander SE, Spencer RJ (2006) Graduate Students and the Culture of Authorship. Ethics Behav 16: 217-232.

7. Hren D, Sambunjak D, Ivanis A, Marusic M, Marusic A (2007) Perceptions of authorship criteria: effects of student instruction and scientific experience. J Med Ethics 33: 428-432.

8. Gaberson KB (2009) Co-author or Teacher? AORN J 90: 19-22.

9. American Counseling Association (2014) Code of ethics. Aust N Z J Psychiatry 26: 677-678.

10. General Medical Council (2009) Tomorrow's Doctors-Outcomes and standards for undergraduate medical education 1-108.

11. AAMFT Code of Ethics American Association for Marriage and Family Therapy.

12. 2016 APA Ethics Committee Rules and Procedures.

13. American Counseling Association.

14. Clement TP (2014) Authorship matrix: a rational approach to quantify individual contributions and responsibilities in multi-author scientific articles. Sci Eng Ethics 20: 345-361.

15. Gobo G (2004) Sampling, representativeness and generalizability. Qual Res Pract 435-456. 